\title{
Reduction of the Early Autogenous Shrinkage of High Strength Concrete
}

\author{
Drago Saje \\ Faculty of Civil and Geodetic Engineering, University of Ljubljana, Jamova cesta 2, SI-1000 Ljubljana, Slovenia \\ Correspondence should be addressed to Drago Saje; drago.saje@fgg.uni-lj.si
}

Received 1 May 2015; Accepted 9 July 2015

Academic Editor: Robert Cerný

Copyright (C) 2015 Drago Saje. This is an open access article distributed under the Creative Commons Attribution License, which permits unrestricted use, distribution, and reproduction in any medium, provided the original work is properly cited.

\begin{abstract}
The results of a laboratory investigation on the early autogenous shrinkage of high strength concrete, and the possibilities of its reduction, are presented. Such concrete demonstrates significant autogenous shrinkage, which should, however, be limited in the early stages of its development in order to prevent the occurrence of cracks and/or drop in the load-carrying capacity of concrete structures. The following possibilities for reducing autogenous shrinkage were investigated: the use of low-heat cement, a shrinkagereducing admixture, steel fibres, premoistened polypropylene fibres, and presoaked lightweight aggregate. In the case of the use of presoaked natural lightweight aggregate, with a fraction from 2 to $4 \mathrm{~mm}$, the early autogenous shrinkage of one-day-old high strength concrete decreased by about $90 \%$, with no change to the concrete's compressive strength in comparison with that of the reference concrete.
\end{abstract}

\section{Introduction}

During the process of hardening of concrete, which follows the mixing stage, water from the fresh concrete mix, during mixing, accumulates in the voids, pores, and capillaries of the mixture. Water binds itself onto the grains of the binder as well as moving into the surroundings, whose relative humidity is usually less than that of the concrete. In order to move this water from the tiny voids, as well as the layers of water on the walls of the voids, considerable forces are needed to overcome the surface tension in the menisci as well as the forces of adhesion which bind the water onto the surface of voids. These forces act on the load-bearing structure of the concrete which has, at this time, a relatively low stiffness, causing large deformations of the concrete element, which leads to damage to the latter. In order to prevent such damage, to the greatest extent possible, it is necessary to limit these deformations, which are known as autogenous deformations or autogenous shrinkage. Excessive autogenous deformations, which cause damage to structures, are undesirable, and attempts need to be made to reduce their intensity by means of appropriate measures.

Low hydration cement, which contain a predominant amount of belite, can be used, in which case the cement hydration process is less intense than that which occurs in the case of alite hydration. This is expressed by a lower level of released energy and lower water consumption $[1,2]$.

Shrinkage-reducing admixtures (SRA) can also be used, which, at the typically recommended addition rates, are, in general, able to reduce the surface tension of the pore solution by $50 \%$ or even more $[3,4]$. They mainly contain hexylene glycol, but they do not contain chlorides and do not cause corrosion to the reinforcement. The tensile forces which occur during the movement of water inside the concrete are reduced due to the reduced surface tension of the water in the capillaries.

In the case of concrete with low water-binder ratios, the amount of water is relatively small, so that inside the finest capillary pores it is soon used up, resulting in the occurrence of large forces inside a relatively flexible structure. For this reason, concrete frequently exhibits, already within the first 24 hours after mixing, very rapid shrinking [2]. With the aim of reducing this high level of shrinkage, attempts can be made to cure the concrete internally. The relatively large surface tension forces inside the menisci of the fine capillaries, as well as the large forces which occur due to the removal of surface layers of water from inside the pores, have to be reduced, although at the same time care must be taken, when adding 
water to the concrete, not to weaken its structure and thus also the load-bearing capacity of the concrete element.

If the concrete has internal reservoirs of water, then the water from the fine capillary pores can be used up later, in concrete that already has higher stiffness. Such reservoirs can be provided by means of presoaked lightweight aggregate, premoistened polypropylene fibres, and superabsorbing polymers $[5,6]$.

The results of experimental investigations and their numerical simulations performed by various researchers [710] have shown that, by adding short strengthening fibres to the concrete, it is possible to improve the mechanical properties, as well as some other important properties, in comparison with comparable plain concrete. Bayasi and Zeng [7], who investigated the influence of dry polypropylene fibers on the compressive strength of fiber-reinforced normal-strength concrete, found that concrete compressive strength increased by $15 \%$ when reinforced with $1.27 \mathrm{~cm}$ long dry polypropylene fibers with a volumetric content of $0.1 \%$ and by $19 \%$ in the case of a volumetric content of $0.3 \%$, whereas at a volumetric content of $0.50 \%$ it decreased by $2.5 \%$ compared with concrete having no reinforcing fibers. Through the addition of steel fibres, according to Paillere et al. [8], an increase of approximately $15 \%$ in the compressive strength of the composite can be obtained, whereas according to Thomas and Ramaswamy [9] a 10\% increase can be obtained, compared with the compressive strength of a comparable concrete without fibres. Swamy [10] has indicated that, as well as causing an increase in compressive strength, the contained steel fibres also give rise to an important increase in the deformation capacity of the composite when compared to that of the equivalent concrete without fibres.

\section{Basic Principles of Early Concrete Shrinkage}

Volumetric changes in the form of shrinkage or swelling begin as the cement starts to bind in the concrete, depending on the curing conditions. In the case when, during the hydration process, continuous supply of water is available to all the pores of the cement paste, concrete swelling occurs. Otherwise, if no such water is available, the concrete begins to shrink.

The shrinkage of concrete consists of chemical and autogenous shrinkage, as well as shrinkage due to drying, plastic shrinkage, shrinkage due to temperature changes, and shrinkage due to carbonation. Autogenous shrinkage of concrete is caused by self-desiccation in the pore system of the hardened cement paste, when water is consumed during the cement hydration process. Chemical shrinkage of the cement paste consists of a reduction in the volume of the cement paste which occurs due to the chemical binding of water which occurs in the same process. During the chemical reaction between the cement and the water, heat is released, which causes an increase in the temperature of the concrete and thus deformation of the latter due to this temperature change.

During the cement hydration process, water is consumed for the formation of the hydration products. As this process proceeds, the volume of the pores increases as a result of the
TABLE 1: The mineral composition of the used types of cement clinker (Bogue).

\begin{tabular}{llcccc}
\hline Cement & $\begin{array}{c}\text { Blaine } \\
{\left[\mathrm{m}^{2} / \mathrm{kg}\right]}\end{array}$ & $\begin{array}{c}\mathrm{C}_{3} \mathrm{~S} \\
(\text { alite })\end{array}$ & $\begin{array}{c}\mathrm{C}_{2} \mathrm{~S} \\
(\text { belite })\end{array}$ & $\mathrm{C}_{3} \mathrm{~A}$ & $\mathrm{C}_{4} \mathrm{AF}$ \\
\hline CEM II/A-S 42.5R & 355 & $64 \%$ & $15 \%$ & $9 \%$ & $9 \%$ \\
CEM I 52.5R & 440 & $64 \%$ & $15 \%$ & $9 \%$ & $9 \%$ \\
CEM I 42.5LH & 367 & $34 \%$ & $46 \%$ & $1.5 \%$ & $15 \%$ \\
\hline
\end{tabular}

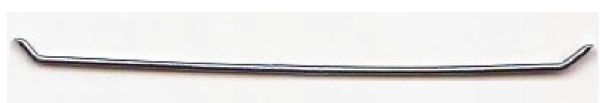

FIGURE 1: The steel fibre IRI 50/30. Steel fibres were added to some of the concrete mixtures.

chemical shrinkage of the cement paste. According to Boyle's law, an increased volume of closed pores is associated with a reduction in the air pressure inside the pores [11]. This reduction in pressure has an indirect effect on the relative humidity in the pores. After thermodynamic equilibrium has been established in the pores of the cement paste, free capillary water evaporates first, followed by the water from the adsorption surface layers of the walls of the pores. The reduction in the thickness of these adsorption layers causes the occurrence of tensile stresses and significant corresponding deformations in these layers, which is difficult for the structure, with its still low stiffness, to resist. In the initial period of the hardening process, when the modulus of elasticity of the cement paste is still relatively low, these tensile stresses can also cause large external deformations, known as autogenous shrinkage. The autogenous shrinkage of high strength concrete usually makes up about half of the total shrinkage, with more than one half of the final autogenous shrinkage occurring during the first 24 hours after mixing of the concrete $[2,12]$.

\section{Materials}

3.1. Cement. Three different types of cement were used to make the experimental concrete mixes: rapid hardening Portland slag cement CEM II/A-S 42.5R, rapid hardening Portland cement CEM I 52.5R, and the Portland cement with a low heat of hydration, CEM I 42.5LH, all of which are produced at the same cement factory. The composition of the clinker in this cement is shown in Table 1.

3.2. Aggregates. The test specimens of all the investigated concrete were prepared from washed and crushed limestone aggregate, with a maximum nominal grain size of $16 \mathrm{~mm}$, with the addition of fine silica sand. The silica sand, the aggregate fraction $0-2 \mathrm{~mm}$, the aggregate fraction $2-4 \mathrm{~mm}$, the aggregate fraction $4-8 \mathrm{~mm}$, and the aggregate fraction $8-$ $16 \mathrm{~mm}$ represent $15 \%, 18 \%, 27 \%, 15 \%$, and $25 \%$ of the total volume of the aggregate used, respectively. The densities of limestone aggregate and silica sand amounted to $2700 \mathrm{~kg} / \mathrm{m}^{3}$ and $2710 \mathrm{~kg} / \mathrm{m}^{3}$, respectively. The compressive strength and 
TABLE 2: Properties of the used steel fibres.

\begin{tabular}{lcccc}
\hline Steel fibres & $\begin{array}{c}\text { Fibre length } \\
{[\mathrm{mm}]}\end{array}$ & $\begin{array}{c}\text { Equivalent fibre diameter } \\
{[\mathrm{mm}]}\end{array}$ & $\begin{array}{c}\text { Fibre tensile strength } \\
{[\mathrm{MPa}]}\end{array}$ & $\begin{array}{c}\text { Fibre class } \\
\text { (ASTM A 820) }\end{array}$ \\
\hline IRI 50/30 & 30 & 0.5 & 900 & Type 1 \\
\hline
\end{tabular}

TABLE 3: Properties of the used polypropylene fibres.

\begin{tabular}{lcccc}
\hline $\begin{array}{l}\text { Density } \\
\left(\mathrm{g} / \mathrm{cm}^{3}\right)\end{array}$ & $\begin{array}{c}\text { Length } \\
(\mathrm{mm})\end{array}$ & $\begin{array}{c}\text { Cross section } \\
(\mu \mathrm{m})\end{array}$ & $\begin{array}{c}\text { Tensile strength } \\
(\mathrm{MPa})\end{array}$ & $\begin{array}{c}\text { Modulus of elasticity } \\
(\mathrm{MPa})\end{array}$ \\
\hline 0.91 & 12 & $35 \times(250-600)$ & $340-500$ & $8500-12500$ \\
\hline
\end{tabular}

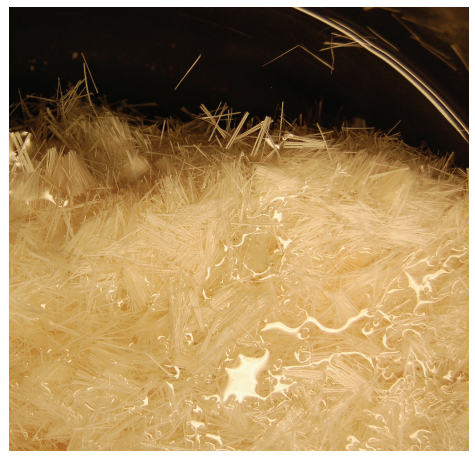

(a) Moistening of fibres

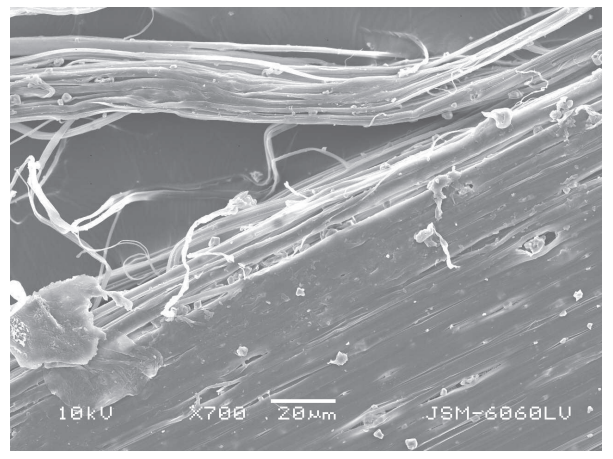

(b) Microimage of a fibre

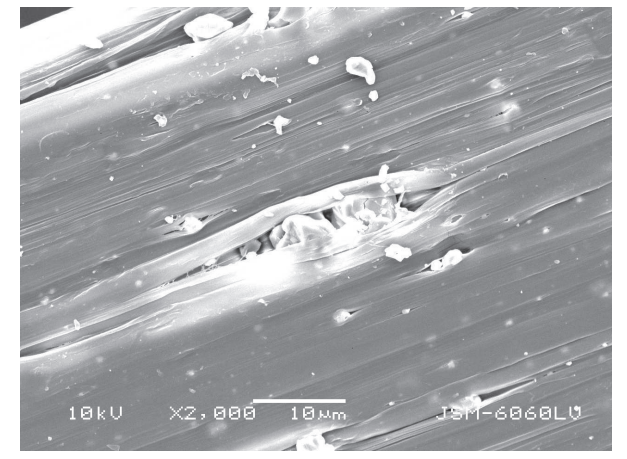

(c) A furrowed fibre surface

Figure 2: The polypropylene fibres which were added to some other concrete mixes.

modulus of elasticity of the stone aggregate amounted to $178 \mathrm{MPa}$ and $243 \mathrm{GPa}$, respectively.

3.3. Steel Fibres. The properties of the steel fibres which were added to some of the concrete mixes are given in Figure 1 and Table 2. The influence of steel fibres on the shrinkage of steel fibre reinforced concrete, with a water-to-binder ratio of 0.36 , was investigated at a fibre volume content of $0.75 \%$.

3.4. Polypropylene Fibres. Some of the other concrete mixes were reinforced by previously moistened polypropylene fibres, as shown in Figure 2. The properties of these fibres are presented in Table 3.

3.5. Lightweight Aggregate. An internal reservoir of water, contributing $12 \%$ of the total volume of the aggregate, that is, presoaked natural lightweight aggregate "Lehnjak," with fractions from 0 to $2 \mathrm{~mm}$ or 2 to $4 \mathrm{~mm}$, was used. The porosity of this aggregate, which is of sedimentary origin, was between $10 \%$ and $15 \%$. Its bulk density amounted to $1440 \mathrm{~kg} / \mathrm{m}^{3}$.

3.6. Chemical Admixtures. In order to ensure adequate workability F2 [13] at a relatively low water-to-binder ratio, a naphthalene or polycarboxylate type of superplasticizer was used. The naphthalene based superplasticizer was in a dry state with a density of $2.2 \mathrm{~kg} / \mathrm{dm}^{3}$ and the polycarboxylate based superplasticizer was in a liquid state with its density of $1.05 \mathrm{~kg} / \mathrm{dm}^{3}$.
In order to reduce the early autogenous shrinkage of the tested specimens, the shrinkage-reducing admixture in a liquid state, which contains hexylene glycol, was used. Its density amounted to $0.92 \mathrm{~kg} / \mathrm{dm}^{3}$.

\section{Testing Procedures}

The test specimens were made from six different mixtures of high strength concrete, designated M1 to M6, and three mixtures of a comparable concrete, designated $\mathrm{C} 1$ to $\mathrm{C} 3$. The total content of the binder in each of the mixtures was $400 \mathrm{~kg} / \mathrm{m}^{3}$ of the composite, $90 \%$ of which was cement $\left(360 \mathrm{~kg} / \mathrm{m}^{3}\right)$ and $10 \%$ was silica fume $\left(40 \mathrm{~kg} / \mathrm{m}^{3}\right)$. Mixture M1 contained the low-heat cement, mixture M2 the shrinkagereducing admixture, mixture M3 the steel fibres, mixture M4 the previously moistened polypropylene fibres (immersed for 24 hours in water), mixture M5 the presoaked lightweight aggregate fraction 0-2 $\mathrm{mm}$ (immersed for 24 hours in water), and mixture M6 the presoaked lightweight aggregate fraction 2-4 $\mathrm{mm}$ (immersed for 24 hours in water) and cement CEM I 52.5R. The compositions and properties of the fresh and hardened concrete are given in Table 4.

4.1. Preparation of the Specimens. Measurements of early autogenous concrete shrinkage were performed on three sealed prisms from each mix, each prism being of size $10 \times 10 \times 40 \mathrm{~cm}$, whereas the compression strength of the investigated concrete was determined on test cubes with edges of $15 \mathrm{~cm}$ (at least three cubes for each mix). 
TABLE 4: Mix proportions of the composites.

\begin{tabular}{|c|c|c|c|c|c|c|c|c|c|}
\hline Mixture & $\mathrm{C} 1$ & M1 & $\mathrm{C} 2$ & M2 & M3 & M4 & M5 & $\mathrm{C} 3$ & M6 \\
\hline $\begin{array}{l}\text { Fine aggregate } 0-4 \mathrm{~mm} \\
\left(\mathrm{~kg} / \mathrm{m}^{3}\right)\end{array}$ & 1130 & 1138 & 1138 & 1137 & 1126 & 1126 & 911 & 1138 & 911 \\
\hline $\begin{array}{l}\text { Coarse aggregate } 4-16 \mathrm{~mm} \\
\left(\mathrm{~kg} / \mathrm{m}^{3}\right)\end{array}$ & 752 & 758 & 758 & 757 & 750 & 750 & 758 & 758 & 758 \\
\hline $\begin{array}{l}\text { Lightweight aggregate } 0-2 \mathrm{~mm} \\
\left(\mathrm{~kg} / \mathrm{m}^{3}\right)\end{array}$ & - & - & - & - & - & - & 121 & - & - \\
\hline $\begin{array}{l}\text { Lightweight aggregate } 2-4 \mathrm{~mm} \\
\left(\mathrm{~kg} / \mathrm{m}^{3}\right)\end{array}$ & - & - & - & - & - & - & - & - & 121 \\
\hline Type of cement & RII & LH & RII & RII & RII & RII & RII & RI & $\mathrm{RI}$ \\
\hline Steel fibres (\% by volume) & - & - & - & - & 0.75 & - & - & - & - \\
\hline $\begin{array}{l}\text { Polypropylene fibres } \\
\text { (\% by volume) }\end{array}$ & - & - & - & - & - & 0.75 & - & - & - \\
\hline $\begin{array}{l}\text { Shrinkage-reducing admixture } \\
\text { (\% by weight of the binder) }\end{array}$ & - & - & - & 5.00 & - & - & - & - & - \\
\hline Water-to-binder ratio & 0.40 & 0.40 & 0.36 & 0.36 & 0.36 & 0.36 & 0.36 & 0.36 & 0.36 \\
\hline $\begin{array}{l}\text { Naphthalene based superplasticizer } \\
\text { (\% by weight of the binder) }\end{array}$ & - & - & 2.05 & 2.05 & 2.05 & 2.05 & 2.05 & 2.05 & 2.05 \\
\hline $\begin{array}{l}\text { Polycarboxylate based superplasticizer } \\
\text { (\% by weight of the binder) }\end{array}$ & 3.70 & 3.70 & - & - & - & - & - & - & - \\
\hline
\end{tabular}

Key: CEM I 52.5R (RI), CEM II/A-S 42.5R (RII), CEM I 42.5LH (LH).

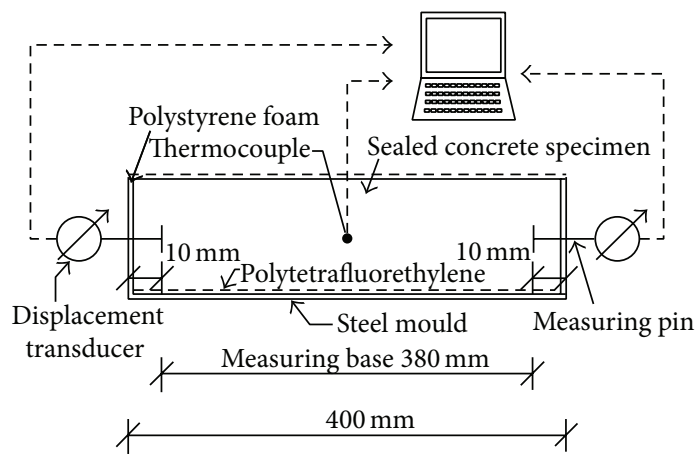

FigURE 3: Schematic representation of the method of measurement of test specimen shrinkage.

The autogenous shrinkage measurements were performed in a climatic chamber at a constant temperature of $22 \pm 3^{\circ} \mathrm{C}$ and at a relative humidity of $70 \pm 5 \%$.

4.2. Autogenous Shrinkage Tests. Computer-controlled measurements of the early autogenous shrinkage of the sealed test specimens were performed, from the beginning of concrete hardening onwards, in accordance with the provisions of the corresponding Japanese standard [14, 15], by means of an electronic displacement transducer with a precision of $10^{-3} \mathrm{~mm}$ (Figure 4). A polytetrafluorethylene sheet was inserted between the test specimen and the base in order to reduce the friction between the two surfaces (Figure 3 ).

The moulds for the preparation of the test specimens for the measurement of autogenous shrinkage, over the first 24 hours, were adapted so that holes were bored through their front steel plates for the insertion of shrinkage measurement

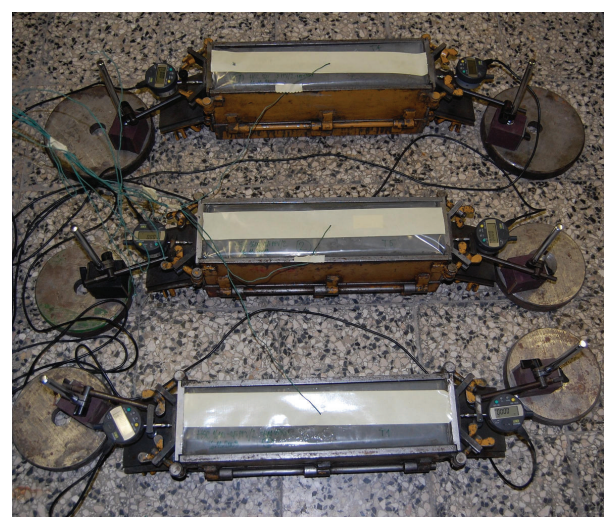

FIgURE 4: Measurement of the autogenous shrinkage of a test specimen.

pins. The latter were inserted in such a manner that the length of the measuring base was $380 \mathrm{~mm}$. The temperature in the middle of the specimen was measured by means of a thermocouple.

The development over time of the autogenous shrinkage of a test specimen $\left(\varepsilon_{c a}\right)$ is determined by the sum of the development over time of the measured deformations $\left(\varepsilon_{c}=\right.$ $\Delta L / L)$ and the temperature expansion $\left(\varepsilon_{(\Delta T)}=\alpha_{T} \cdot \Delta T\right)$ of the specimens due to variations, over time, in temperature. The temperature of the test specimens varied significantly during the first 24 or 48 hours, that is, during the period of rapid setting of the cement, but was later in equilibrium with the ambient temperature of the environment. The variations in the length of the test specimen over time, due to the varying temperature during the period of rapid setting of 
TABLE 5: Comparison of the autogenous shrinkage of 24- and 48-hour-old concrete which differed according to the type of cement, and their associated 28-day compressive strengths.

\begin{tabular}{|c|c|c|c|c|}
\hline Concrete mix & Additional measure & $\begin{array}{c}\mathcal{E}_{c a, 24 \text { hours }} \\
{[\% \mathrm{o}]}\end{array}$ & $\begin{array}{c}\mathcal{E}_{c a, 48 \text { hours }} \\
{[\% \mathrm{o}]}\end{array}$ & $\begin{array}{c}f_{c m, 28 \text { days }} \\
{[\mathrm{MPa}]}\end{array}$ \\
\hline $\mathrm{C} 1$ & 1 & -0.216 & -0.205 & 80.6 \\
\hline M1 & Use of low-heat cement & Below detection level & -0.027 & 74.0 \\
\hline
\end{tabular}

TABLE 6: Comparison of the autogenous shrinkage of 24- and 48-hour-old concrete, without and with a shrinkage-reducing admixture, and their associated 28-day compressive strengths.

\begin{tabular}{lcccc}
\hline Concrete mix & Additional measure & $\varepsilon_{c a, 24 \text { hours }}$ & $\begin{array}{c}\varepsilon_{c a, 48 \text { hours }} \\
{[\% \text { o }}\end{array}$ & $\begin{array}{c}f_{c m, 28 \text { days }} \\
{[\mathrm{MPa}]}\end{array}$ \\
\hline $\mathrm{C} 2$ & $/$ & -0.203 & -0.235 & 81.4 \\
M2 & Use of a shrinkage-reducing admixture & -0.050 & -0.030 & 77.9 \\
\hline
\end{tabular}

the cement, were determined analytically, taking into account the temperature expansion coefficient of the concrete and the measured variations, over time, of the temperature. A value of $\alpha_{T, f}=1.48 \cdot 10^{-5}$, which had been determined by separate measurements [2], was assumed as the temperature expansion coefficient of the fresh concrete, and a value of $\alpha_{T, h}=1.0 \cdot 10^{-5}$, was assumed as the temperature expansion coefficient of the hardened concrete [15]. The concrete was considered fresh until the temperature of the specimen began to rise $\left(\alpha_{T}=\alpha_{T, f}\right)$, which roughly corresponded to the start of the rapid hardening of the concrete. After rapid hardening had been completed, that is, from around the 24 th hour onwards, the concrete was regarded as hardened $\left(\alpha_{T}=\alpha_{T, h}\right)$. During the intermediate period of time, when the temperature of the test specimens changed more rapidly, the temperature expansion coefficient was determined by linear interpolation between the values for fresh concrete $\left(\alpha_{T, f}\right)$ and hardened concrete $\left(\alpha_{T, h}\right)$.

\section{Test Results and Discussion}

In Tables 5 to 8 , values of the autogenous shrinkage of the high strength concrete measured at the age of 24 hours and 48 hours, $\varepsilon_{c a, 24 \text { hours }}$ and $\varepsilon_{c a, 48 \text { hours }}$, and of the compressive strength of the concrete at the age of 28 days, $f_{c m}, 28$ days, are compared.

After 24 hours, the contraction of concrete M1, which contained the low-heat cement, could not be detected by the used measuring technique. After 48 hours, this concrete developed approximately one-eighth (13\%) of the shrinkage measured on the comparable concrete $\mathrm{Cl}$ (Table 5). The autogenous shrinkage of the comparable concrete $\mathrm{Cl}$ was, after 48 hours, even slightly less than that measured after 24 hours due to thermodynamic effects. This physical phenomenon is the result of the thermodynamic equilibrium in the pores of the hardened cement paste. As the temperature in the concrete begins to fall, the concrete shrinks because of its linear coefficient of thermal expansion, resulting in a decrease in the volume of the closed pores within the hardened cement paste. Due to the reduction in the volume of the closed pores, the relative humidity inside them increases according to the laws of thermodynamics. Thus, if there is a reduction in the tensile forces acting on the pore walls, then there is a decrease in the autogenous shrinkage of the concrete. Because of the drop in the air temperature inside the closed pores at thermal equilibrium, the relative air humidity rises, which results in a further decrease in the autogenous shrinkage of the concrete.

The measured 28-day compressive strength of concrete M1, which contained the low-heat cement, represented $92 \%$ of the 28-day compressive strength of the comparable concrete $\mathrm{C} 1$.

The autogenous shrinkage of the concrete containing lowheat, mainly belite cement, CEM I 42.5LH, was less than that of the concrete containing rapid hardening, predominantly alite cement, CEM II 42.5R, due to the fact that less water is consumed in the hydration of belite $[1,2]$. Reduced water consumption means less self-desiccation in the cement paste pores, and smaller forces acting on the pore walls, resulting in lower autogenous shrinkage of the concrete.

In the case of the concrete M2, which contained the shrinkage-reducing admixture, about quarter (25\%) of the shrinkage developed over a period of 24 hours compared to that which was measured on the comparable concrete C2 (Table 6). The 28-day compressive strength of the concrete containing the shrinkage-reducing admixture amounted to $96 \%$ of the 28 -day compressive strength of the comparable concrete C2.

The shrinkage-reducing admixture reduces the surface tension of the pore solution. According to the Kelvin-Laplace equation $\sigma_{\text {cap }}=2 \gamma \cos \theta / r$, where $\sigma_{\text {cap }}$ is the capillary stress, $\gamma$ is the surface tension of the pore solution, and $\theta$ is the wetting/contact angle between the pore solution and solids, it follows that, in the case of a reduction in surface tension, the capillary stresses decrease, so that the autogenous shrinkage decreases, too.

In the case of the concrete M3, which contained steel fibres, about four-fifths (81\%) of the shrinkage developed over a period of 24 hours compared to that which was measured on the comparable concrete C2 (Table 7). The 28-day compressive strength of this steel-fibre reinforced concrete amounted to $113 \%$ of the 28 -day compressive strength of the comparable concrete $\mathrm{C} 2$. 
TABLE 7: Comparison of the autogenous shrinkage of 24- and 48-hour-old non-reinforced and fibre-reinforced concretes, and their associated 28-day compressive strengths.

\begin{tabular}{lcccc}
\hline Concrete mix & Additional measure & $\begin{array}{c}\varepsilon_{c a, 24 \text { hours }} \\
{[\% \text { o }]}\end{array}$ & $\begin{array}{c}\varepsilon_{c a, 48 \text { hours }} \\
{[\% \text { o }]}\end{array}$ & $\begin{array}{c}f_{c m, 28 \text { days }} \\
{[\mathrm{MPa}]}\end{array}$ \\
\hline C2 & $/$ & -0.203 & -0.235 & 81.4 \\
M3 & Added steel fibres & -0.165 & -0.192 & 92.1 \\
M4 & Added premoistened polypropylene fibres & -0.064 & -0.117 & 78.1 \\
\hline
\end{tabular}

TABLE 8: Comparison of the autogenous shrinkage of 24- and 48-hour-old concretes, containing natural crushed stone aggregate or with added presoaked lightweight aggregate, and their associated 28-day compressive strengths.

\begin{tabular}{|c|c|c|c|c|}
\hline Concrete mix & Additional measure & $\begin{array}{c}\mathcal{E}_{c a, 24 \text { hours }} \\
{[\% 0]}\end{array}$ & $\begin{array}{c}\mathcal{E}_{c a, 48 \text { hours }} \\
{[\% \text { o }]}\end{array}$ & $\begin{array}{c}f_{c m, 28 \text { days }} \\
{[\mathrm{MPa}]}\end{array}$ \\
\hline $\mathrm{C} 2$ & I & -0.203 & -0.235 & 81.4 \\
\hline M5 & Added presoaked lightweight aggregate, fraction $0-2 \mathrm{~mm}$ & -0.186 & -0.185 & 89.1 \\
\hline $\mathrm{C} 3$ & l & -0.293 & -0.303 & 83.0 \\
\hline M6 & Added presoaked lightweight aggregate, fraction $2-4 \mathrm{~mm}$ & -0.028 & -0.053 & 84.4 \\
\hline
\end{tabular}

In the case of young composites, the stiffness and loadbearing capacity of the steel fibres are relatively high in comparison with those of the, as yet not hardened, cement paste. For this reason, they affect the general properties of the young steel-fibre reinforced concrete. The fibre forces are transferred from the fibres into the concrete through the bond along the stress transfer lengths and through the snubbing zones at the cracks and additionally through the end-hooks by the steel fibres [16]. This is the reason for the reduction in autogenous shrinkage which occurs in the case of concrete that is reinforced with steel fibres.

In the case of the concrete M4, which contained previously moistened polypropylene fibres, about one-third (32\%) of the shrinkage developed over a period of 24 hours compared to that which was measured on the comparable concrete C2 (Table 7). The 28-day compressive strength of the concrete which was reinforced with saturated polypropylene fibres amounted to $96 \%$ of the 28 -day compressive strength of the comparable concrete $\mathrm{C} 2$.

The polypropylene fibres, which had been previously immersed in water for 24 hours, act in concrete as internal reservoirs of water. Taking into account the fact that the wetting angle of the propylene fibres is less than $90^{\circ}$ [17], it can be assumed that these fibres are not absolutely hydrophobic. Apart from this, 3-dimensional pores are formed between individual fibres within bunches of fibres [5]. Due to the capillary osmotic pressure, these 3-dimensional pores or channels between the fibres pick up the water due to soaking, which causes significant attractive forces between the soaked fibres, even in the case when the wetting angle is considerably greater than $0^{\circ}$ but less than $90^{\circ}$ [18]. The attractive forces between the fibres retain water during the mixing of the concrete, but the cement hydration process starts to consume this water as soon as the free water available for mixing is consumed. If the hydrating binder continues to be supplied with water, then the development of larger autogenous shrinkage can be prevented.

In the case of the concrete M5, which contained natural crushed stone aggregate to which a presoaked lightweight aggregate of fraction $0-2 \mathrm{~mm}$ had been added, about tenelevenths (92\%) of the shrinkage developed over a period of 24 hours compared to that which was measured on the comparable concrete $\mathrm{C} 2$, which contained only natural crushed stone aggregate (Table 8 ). The 28-day compressive strength of the concrete M5 amounted to $109 \%$ of the 28 -day compressive strength of the comparable concrete $\mathrm{C} 2$.

In the case of the concrete M6, which contained natural crushed stone aggregate to which a presoaked lightweight aggregate of fraction 2-4 $\mathrm{mm}$ had been added, about onetenth $(10 \%)$ of the shrinkage developed over a period of 24 hours compared to that which was measured on the comparable concrete $\mathrm{C} 3$, which contained only natural crushed stone aggregate (Table 8). The 28-day compressive strength of the concrete M6 amounted to $102 \%$ of the 28-day compressive strength of the comparable concrete C3.

The increased porosity of the lightweight aggregate of fraction 2-4 mm made the capturing of larger amounts of water than the lightweight aggregate of fraction $0-2 \mathrm{~mm}$ possible. The finer lightweight aggregate contained fewer appropriate capillaries and more dust particles.

In the case of concrete containing presoaked lightweight aggregate, the formation of a better-quality transition zone between the grains of the aggregate and the hardened cement paste apparently makes it possible for this type of concrete to be able to transfer compressive stresses which even slightly exceed the load-carrying capacity of comparable concrete. It is remarkable that the comparable concrete contains the same proportion of aggregate as the investigated concrete and that its aggregate consists of just natural crushed stone whose strength exceeds that of the lightweight aggregate.

\section{Practical Relevance and Potential Applications}

The antishrinkage measures which are mentioned in the paper can be applied in the design and construction of high strength concrete structures in cases where reduced 
shrinkage is a requirement. The degree of cracking of concrete elements is less if the shrinkage coefficient of the concrete is relatively low, so that, via reduced permeability, the durability of structures such as industrial floors, as well as dams and other structures located in marine environments, can be ensured. In the case of prestressed concrete structures such as bridges, since there is less shrinkage of the concrete, the losses which can occur in the prestressing forces acting in the cables are also reduced.

\section{Conclusions}

The conclusions resulting from the experimental research analysed in this paper can be summarized as follows:

(i) In the case of high strength concrete, the development of autogenous shrinkage can be limited by various measures. During the cement hydration process in concrete which is made from predominantly belite cement, less water is consumed. The use of a shrinkage-reducing admixture reduces the surface tension of the water in the capillary pore system, whereas the addition of steel fibres increases the stiffness of the concrete matrix. The use of previously moistened fibrillated polypropylene fibres or presoaked lightweight aggregate can provide reservoirs of water during the cement hydration process.

(ii) The early autogenous shrinkage of the 48-hoursold investigated high strength concrete which was internally cured by means of presoaked lightweight aggregate was 21 to $83 \%$ less than that of the comparable concrete made with ordinary aggregate, and their compressive strengths were between 2 and $9 \%$ higher than that of the latter.

(iii) Inside the concrete, presoaked fibrillated polypropylene fibres occur in bundles, in which there is a pore system which retains water. The autogenous shrinkage of two-day-old concrete which contained $0.75 \%$ of previously moistened polypropylene fibres was $50 \%$ less than that of the comparable concrete without fibres.

(iv) Chemical admixtures for the reduction of shrinkage in concrete, which contain hexylene glycol, reduce the surface tension of the water in the pore system of the cement paste. At an age of two days, the autogenous shrinkage of the investigated concrete containing such a shrinkage-reducing admixture was $87 \%$ less than that of the comparable concrete without the shrinkage-reducing admixture, and their compressive strength at 28 days was $4 \%$ less than that of the comparable concrete.

(v) Hooked steel fibres, due to their stiffness and good bonding properties, strengthen the concrete and have a favourable impact on autogenous shrinkage and compressive strength. In the case of the investigated concrete, which contained $0.75 \%$ steel fibres with a length of $30 \mathrm{~mm}$, the early autogenous shrinkage at an age of two days was $18 \%$ less, and their compressive strength was $13 \%$ greater than that of the comparable concrete without fibres.

(vi) The use of low-heat cement in concrete slows down the process of hydration. The autogenous shrinkage of the investigated concrete, which contained low-heat, mainly belite cement, was, after one day, below the detection limit, whereas after two days it was $87 \%$ less than that of the comparable concrete, which contained ordinary predominantly alite cement. The compressive strength of the 28-day-old concrete made with predominantly belite cement was $8 \%$ less than that of comparable concrete made with predominantly alite cement.

\section{Conflict of Interests}

The author declares that there is no conflict of interests regarding the publication of this paper.

\section{References}

[1] A. M. Neville, Properties of Concrete, Longman, Harlow, UK, 1995.

[2] D. Saje, Compressive strength and shrinkage of high strength concrete [Ph.D. thesis], University of Ljubljana, 2001.

[3] D. P. Bentz, "Influence of shrinkage-reducing admixtures on early-age properties of cement pastes," Journal of Advanced Concrete Technology, vol. 4, no. 3, pp. 423-429, 2006.

[4] A. N. M. Lopes, E. F. Silva, D. C. C. Dal Molin, and R. D. T. Filho, "Shrinkage-reducing admixture: effects on durability of high-strength concrete," ACI Materials Journal, vol. 110, no. 4, pp. 365-374, 2013.

[5] D. Saje, B. Bandelj, J. Šušteršic, J. Lopatič, and F. Saje, "Shrinkage of polypropylene fibre reinforced high performance concrete," Journal of Materials in Civil Engineering, vol. 23, no. 7, pp. 941952, 2011.

[6] P. C. Aïtcin, "Internal curing," in Proceedings of the 3rd International Symposium Non-Traditional Cement \& Concrete, pp. 1-7, Brno, Czech Republic, 2008.

[7] Z. Bayasi and J. Zeng, "Properties of polypropylene fibre reinforced concrete," ACI Materials Journal, vol. 90, no. 6, pp. 605-610, 1993.

[8] A. M. Paillere, M. Buil, and J. J. Serrano, "Effect of fiber addition on autogenous shrinkage of silica fume concrete," ACI Materials Journal, vol. 86, no. 2, pp. 139-144, 1989.

[9] J. Thomas and A. Ramaswamy, "Mechanical properties of steel fiber-reinforced concrete," Journal of Materials in Civil Engineering, vol. 19, no. 5, pp. 385-392, 2007.

[10] R. N. Swamy, "Fibre reinforcement of cement and concrete," Matériaux et Constructions, vol. 8, no. 3, pp. 235-254, 1975.

[11] E. A. B. Koenders, Simulation of volume changes in hardening cement-based materials [Ph.D. thesis], Delft University Press, Delft, The Netherlands, 1997.

[12] K. Kovler and O. M. Jensen, "Internal curing of concrete," Stateof-the-Art Report RILEM TC 196-ICC, 2007.

[13] CEN, "CONCRETE-specification, performance, production and conformity," BS EN 206-1:2000, CEN, Brussels, Belgium, 2000 .

[14] JIS Standards, JIS A 1129-1, Methods of Test for Length Change of Mortar and Concrete, JIS Standards, Tokyo, Japan, 2001. 
[15] E. Tazawa, Autogenous Shrinkage of Concrete, E\&FN Spon, London, UK, 1999.

[16] S. J. Foster, "The application of steel-fibres as concrete reinforcement in Australia: from material to structure," Materials and Structures, vol. 42, no. 9, pp. 1209-1220, 2009.

[17] B. Felekoglu, K. Tosun, and B. Baradan, "A comparative study on the flexural performance of plasma treated polypropylene fiber reinforced cementitious composites," Journal of Materials Processing Technology, vol. 209, no. 11, pp. 5133-5144, 2009.

[18] V. Smolej and S. Pejovnik, "Some remarks on the driving force for liquid-phase sintering," Materials Research and Advanced Techniques, vol. 67, no. 9, pp. 603-602, 1976. 

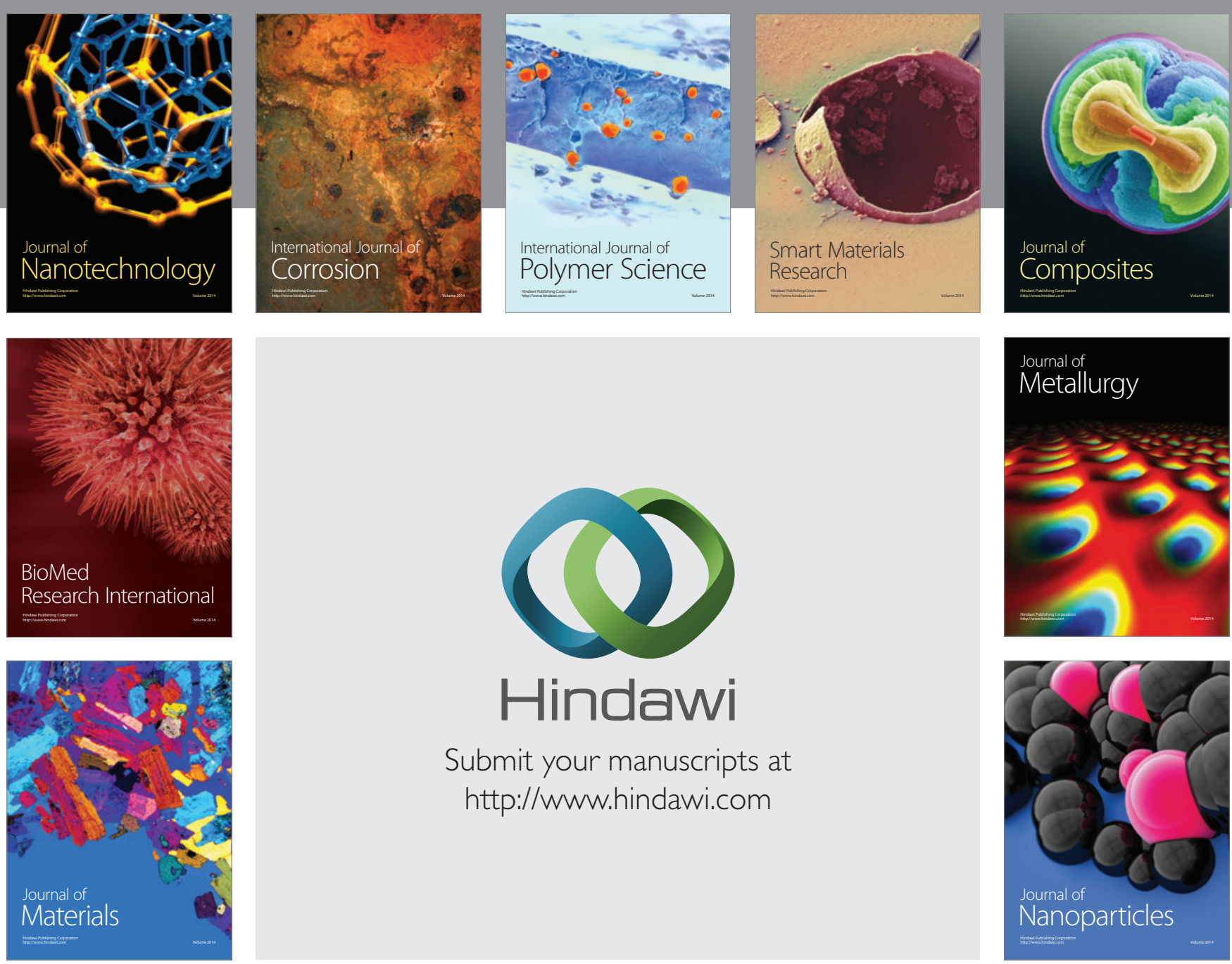

Submit your manuscripts at http://www.hindawi.com
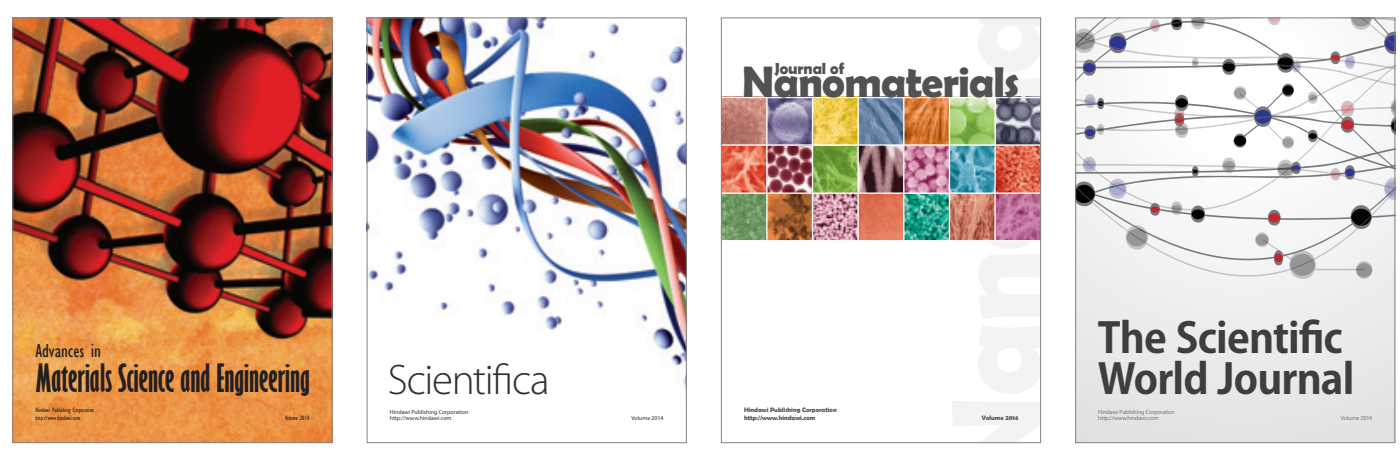

\section{The Scientific World Journal}
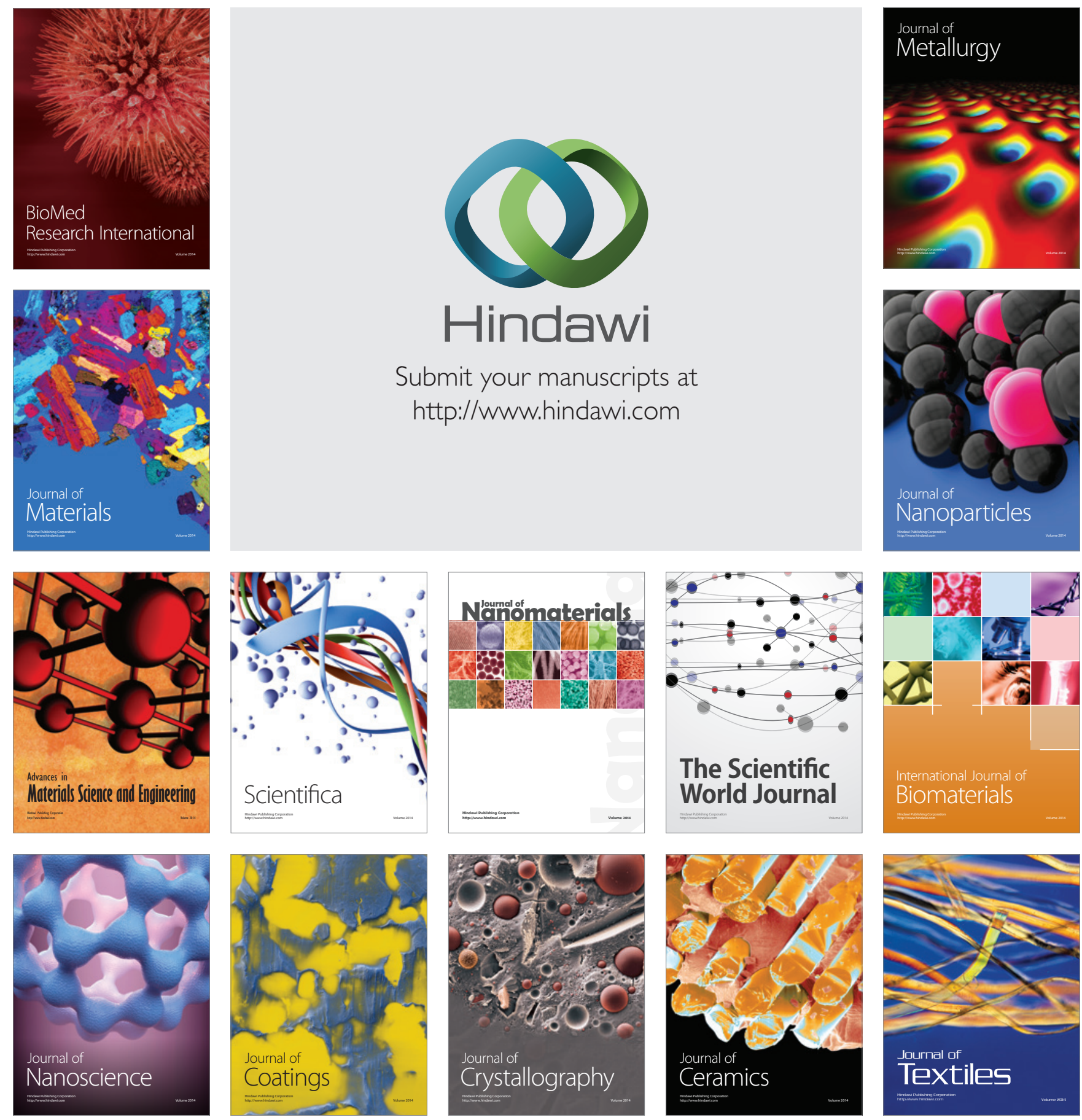